\title{
5-Azacytidine enhances efficacy of multiple chemotherapy drugs in AML and lung cancer with modulation of CpG methylation
}

\author{
MATHIAS FÜLLER $^{1 *}$, MIRIAM KLEIN $^{1 *}$, EVA SCHMIDT ${ }^{1}$, CHRISTIAN ROHDE $^{2}$, \\ STEFANIE GÖLLNER $^{2}$, ISABELL SCHULZE ${ }^{2}$, JIANG QIANLI ${ }^{1}$, WOLFGANG E. BERDEL ${ }^{1}$, \\ BAYRAM EDEMIR $^{2}$, CARSTEN MÜLLER-TIDOW ${ }^{2}$ and PETRA TSCHANTER ${ }^{2}$ \\ ${ }^{1}$ Department of Medicine A, Hematology and Oncology, University of Münster, Münster; \\ ${ }^{2}$ Department of Medicine IV, Hematology and Oncology, University of Halle, Halle, Germany
}

Received September 25, 2014; Accepted November 12, 2014

DOI: 10.3892/ijo.2014.2792

\begin{abstract}
The DNA methyltransferase (DNMT) inhibitory drugs such as 5-azacytidine induce DNA hypomethylation by inhibiting DNA methyltransferases. While clinically effective, DNMT inhibitors are not curative. A combination with cytotoxic drugs might be beneficial, but this is largely unexplored. In the present study, we analyzed potential synergisms between cytotoxic drugs and 5-azacytidine in acute myeloid leukemia (AML) and non-small cell lung cancer (NSCLC) cells. Lung cancer and leukemia cell lines were exposed to low doses of 5 -azacytidine with varying doses of cytarabine or etoposide for AML cells (U937 and HL60) as well as cisplatin or gemcitabine for NSCLC cells (A549 and HTB56) for $48 \mathrm{~h}$. Drug interaction and potential synergism was analyzed according to the ChouTalalay algorithm. Further analyses were based on soft agar colony formation assays, active caspase- 3 staining and BrdU incorporation flow cytometry. To identify effects on DNA methylation patterns, we performed genome wide DNA methylation analysis using $450 \mathrm{~K}$ bead arrays. Azacytidine at low doses was synergistic with cytotoxic drugs in NSCLC and in AML cell lines. Simultaneous exposure to 5-azacytidine with cytotoxic drugs showed strong synergistic activity. In colony formation assays these synergisms were repeatedly verified for 5 -azacytidine $(25 \mathrm{nM})$ with low doses of anticancer agents. 5 -azacytidine neither affected the cell cycle nor increased apoptosis. $450 \mathrm{~K}$ methylation bead arrays revealed $1,046 \mathrm{CpG}$ sites in AML and 1,778 CpG sites in NSCLC cells with signifi-
\end{abstract}

Correspondence to: Dr Petra Tschanter or Professor Carsten MüllerTidow, Department of Medicine IV, Hematology and Oncology, University of Halle, 06120 Halle (Saale), Germany

E-mail: petra.tschanter@uk-halle.de

E-mail: carsten.mueller-tidow@uk-halle.de

${ }^{*}$ Contributed equally

Key words: DNA methyltransferase inhibition, acute myeloid leukemia, non-small cell lung cancer, 5-azacytidine, synergism cant DNA hypomethylation (24-h exposure) to 5-azacytidine combined with the cytotoxic drugs. These $\mathrm{CpG}$-sites were observed in the candidate tumor-suppressor genes MGMT and THRB. Additional incubation time after 24-h treatment led to a 4.1-fold increase of significant hypomethylated CpG-sites in NSCLC cells. These results suggest that the addition of DNA demethylating agents to cytotoxic anticancer drugs exhibits synergistic activity in AML and NSCLC. Dysregulation of an equilibrium of DNA methylation in cancer cells might increase the susceptibility for cytotoxic drugs.

\section{Introduction}

Acute myeloid leukemia (AML) and non-small cell lung cancer (NSCLC) are known to be associated with high lethality despite intensive treatment. With overall 5-year survival rates of 25.7 and $16.6 \%$, respectively (1) the treatment of AML and NSCLC remains an important field of experimental and clinical investigation.

In the last decade, the knowledge and understanding of tumorigenesis increased rapidly. Besides genetic mutations and alterations, epigenetic changes, especially alterations in methylation patterns, have been found in tumor development and progression $(2,3)$. The term 'epigenetics' is defined as any change of gene expression that is not mediated by alterations of the primary nucleotide sequence. Changes of the methylation pattern occur during normal mammalian development and play an important role in tissue-specific gene regulation, genomic imprinting and $\mathrm{X}$-chromosome inactivation by gene silcening (4). In cancer cells, the 5-methyl-cytosine distribution is altered in two directions: while the global methylation level is decreased (5), $\mathrm{CpG}$ islands appear to be hypermethylated (6). These regions often are associated with gene promoters and, therefore, might contribute to cancer-specific silencing of tumor-suppressor-genes (reviewed in ref. 7).

In normal as well as tumor cells, DNA methylation is mainly regulated by the DNA methyltransferase (DNMT) 1, 3a and $3 \mathrm{~b}$ (8). These enzymes catalyze maintenance (DNMT1) $(9,10)$ and de novo methylation (DNMT3a and DNMT3b) $(11,12)$ by adding a methyl group to the cytosine ring (8). As DNMT play an important role in tumorigenesis $(13,14)$, they appear as promising targets for anticancer therapy. 
5-azacytidine (Aza) is a nucleoside analogue that is incorporated into DNA and RNA (15). While high doses result in cytotoxicity (16), low dose Aza leads to DNA hypomethylation by irreversible binding and degradation of DNA methyltransferases (DNMT) $(17,18)$. In vitro and in vivo studies indicate that Aza is able to reactivate epigenetically silenced tumorsuppressor- and chemosensitivity-genes and alter cancer phenotypes by its demethylating action $(19,20)$. To date, it is approved for the treatment of the myelodysplastic syndrome and acute myeloid leukemia with $20-30 \%$ blasts in the bone marrow. There are few reports concerning the treatment of solid tumors (21). Though Aza has proven clinical activity, it does not work curatively.

We hypothesize that DNMT inhibitory drugs may enhance the antitumor activity of cytotoxic agents. Therefore, we exposed AML cell lines to cytarabine (AraC) or etoposide (Eto) and NSCLC cell lines to cisplatin (Cis) or gemcitabine (Gem) alone and in combination with low dose Aza in order to find synergistic drug interactions.

\section{Materials and methods}

Cell culture. We used human leukemic cell lines U937 and HL60 and the NSCLC cell lines A549 (adenocarcinoma) and HTB56 (anaplastic carcinoma). Leukemic cells were maintained in RPMI (Gibco, Carlsbad, CA, USA) and A549 cells in Dulbecco's modified Eagle's medium (DMEM; SigmaAldrich, St. Louis, MO, USA), both supplemented with $10 \%$ fetal calf serum and $1 \%$ penicillin/streptomycin. HTB56 cells were maintained in Minimum Essential Medium (MEM; Gibco), supplemented with $10 \%$ fetal calf serum, $1 \%$ penicillin/streptomycin, $1 \%$ non-essential amino acids (Gibco), $1 \%$ L-glutamine (Sigma-Aldrich) and $1 \%$ sodium pyruvate (Gibco). All cell cultures were maintained in a humified atmosphere of $5 \% \mathrm{CO}_{2}$ at $37^{\circ} \mathrm{C}$. Cells were counted by the test of trypan blue exclusion.

Reagents. All drugs were purchased from Sigma-Aldrich. Aza was diluted in 1X PBS to a final concentration of $50 \mathrm{mM}$, gemcitabine-hydrochloride was diluted in $0.9 \% \mathrm{NaCl}$ to a final concentration of $5 \mathrm{mM}$, cis-diammineplatinum(II)dichloride in sterile $\mathrm{ddH}_{2} \mathrm{O}$ to a final concentration of $5 \mathrm{mM}$, $\beta$-D-arabinofuranoside was diluted in $1 \mathrm{X}$ PBS to a final concentration of $10 \mathrm{mM}$ and etoposide in dimethylsulfoxide (Serva Electrophoresis GmbH, Heidelberg, Germany) to $50 \mathrm{mM}$. Aza, AraC and Eto were stored at $-20^{\circ} \mathrm{C}$, Cis at room temperature and protected from light and $\mathrm{Gem}$ at $4^{\circ} \mathrm{C}$.

Cell proliferation assays. Cell proliferation assays were performed by MTS assays and by counting cells. For MTS assays, AML cells were treated with Aza in a range from 50 to $2000 \mathrm{nM}$ as well as $\operatorname{AraC}(100-2000 \mathrm{nM})$ and Eto (30-3000 nM) alone or in combination with 25 and $100 \mathrm{nM}$ of Aza. NSCLC cells were treated with Aza in a dose range from 25 to $5000 \mathrm{nM}$ as well as Cis $(10-100000 \mathrm{nM})$ and Gem (10-10000 nM) alone or in combination with 25 and $100 \mathrm{nM}$ of Aza. Cell proliferation was measured after 48-h treatment by reduction of 3-(4,5-dimethylthiazol-2-yl)-5-(3-carboxymethoxyphenyl)-2-(4-sulfophenyl)-2H-tetrazolium according to the recommendations of the manufacturer (Promega Corp.,
Fitchburg, WI, USA) at $490 \mathrm{~nm}$ with the Benchmark microplate reader (Bio-Rad Laboratories, Hercules, CA, USA). MTS assays were performed in triplicate.

Drug interactions were evaluated with CalcuSyn Software (Biosoft, Cambridge, UK) according to the median-effect method by Chou and Talalay (22). A combination index (CI) $<0.9$ indicates synergistic drug interactions, a CI of $>1.1$ is antagonistic and a CI between 0.9 and 1.1 stands for additive effects.

To analyze whether sequential or simultaneous combination treatment is superior, low doses of Aza (25 and $100 \mathrm{nM})$ were combined with AraC and Eto in AML cell lines as well as with Gem in NSCLC cell lines. Sequentiell treatment consisted of 48-h treatment with Aza followed by 48-h treatment with the respective drug after removal of Aza. For simultaneous treatment the drugs were exposed to both agents at the same time for $48 \mathrm{~h}$.

Methylcellulose colony-formation assay. After $24 \mathrm{~h}$ of drug treatment, drugs were washed out and equal numbers of viable cells were plated in triplicates in $2.3 \%$ methylcellulose (SigmaAldrich). A549, HL60 and U937 colonies containing >50 cells were quantified after 7 days of incubation under an inverted microscope, HTB56 colonies after 11 days. AML cell lines were treated with $25 \mathrm{nM}$ of Aza, $25 \mathrm{nM}$ of $\mathrm{AraC}, 50 \mathrm{nM}$ of Eto and the respective combinations of Aza and either AraC or Eto. Both NSCLC cell lines were treated with $25 \mathrm{nM}$ of Aza, $25 \mathrm{nM}$ and $50 \mathrm{nM}$ of $\mathrm{Cis}$ and the combination of Aza and both Cis doses. A549 cells were additionally treated with 25 and $50 \mathrm{nM}$ of Gem as well as the combination of Aza and either 25 or $50 \mathrm{nM}$ of Gem.

Bromodeoxyuridine incorporation and fluorescence-activated cell sorting. AML cell lines were treated with $25 \mathrm{nM}$ of Aza, $100 \mathrm{nM}$ of AraC, $100 \mathrm{nM}$ of Eto and the respective combinations of Aza and AraC or Eto. NSCLC cell lines were treated with $25 \mathrm{nM}$ of Aza, $100 \mathrm{nM}$ of Cis, $100 \mathrm{nM}$ of Gem as well as with the respective combinations. After $22 \mathrm{~h}$, bromodeoxyuridine was added for two additional hours of incubation, then cells were stained according to the manufacturer's instructions (BD Biosciences, Franklin Lakes, NJ, USA). BrdU incorporation was analyzed on a FACSCalibur flow cytometer (Becton-Dickinson, San Jose, CA, USA) using BD CellQuest Pro (BD Biosciences).

Active caspase-3 staining and fluorescence-activated cell sorting. A549 and HTB56 cells were treated with $25 \mathrm{nM}$ of Aza, $100 \mathrm{nM}$ of Cis, $100 \mathrm{nM}$ of Cis and the respective combinations for $24 \mathrm{~h}$. After permeabilisation active caspase-3 was measured using phycoerythrin-conjugated anti-activecaspase-3 antibody (BD Biosciences) according to the manufacturer's instructions and analyzed by flow cytometry like described above.

DNA methylation analysis. Cells were treated according to colony formation assays. After $24 \mathrm{~h}$ of treatment, DNA was isolated using the High Pure PCR Template Preparation kit for genomic DNA (Roche Applied Science, Penzberg, Germany) and DNA content was measured with the NanoDrop spectrophotometer ND-1000 ${ }^{\mathrm{TM}}$ (Peqlab Biotechnologie, Erlangen, 

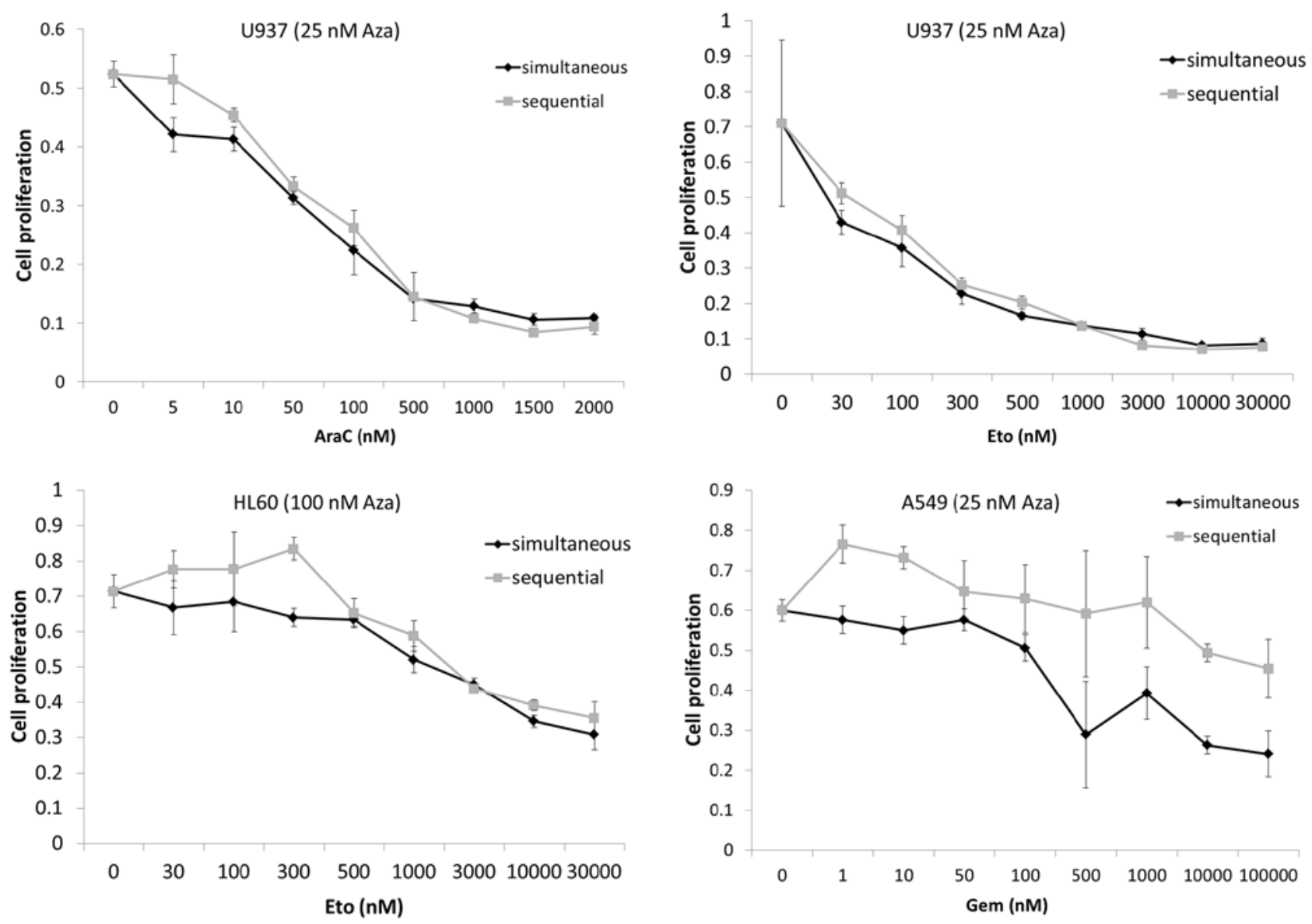

Figure 1. Comparison of sequential and simultaneous Aza combination treatment. Representative growth curves according to MTS-proliferation assays. Forty-eight hours of simultaneous treatment showed equal or even superior effectiveness in all four cell lines compared to sequential treatment ( $\mathrm{n} \geq 2$ ). Upper panel shows results of U937 cells treated with $25 \mathrm{nM}$ Aza in combination with different concentrations of AraC (left panel) oder Eto (right panel). Lower panel shows the results of HL60 trated with $100 \mathrm{nM}$ Aza in combination with different combinations of Eto (left panel) and A549 cells treated with $25 \mathrm{nM}$ Aza in combination with different concentrations of Gem.

Germany). DNA methylation was analyzed by $450 \mathrm{~K}$ bead arrays using EZ-96 DNA Methylation ${ }^{\mathrm{TM}}$ kit (Zymo Research, Irvine, CA, USA) with optimized PCR conditions according to the manual. Analysis of methylation data was performed by BRB-ArrayTools developed by Dr Richard Simon and the BRB-ArrayTools Development Team.

Statistical analysis. All data are shown as mean plus standard deviation (SD), if not otherwise specified. Statistical differences between two groups were calculated by the Student's t-test. A p-value of $<0.05$ was considered as indicating significant differences.

\section{Results}

Simultaneous and sequential Aza combinational treatment show similar effectiveness. Four human cancer cell lines (A549, HL60, HTB56 and U937) were treated with simultaneous and sequential Aza containing drug combinations to evaluate whether one form of application would be superior.

Proliferation assays (Fig. 1) indicated no advantage of the sequential over the simultaneous application. Considering these results we chose the simultaneous application for further experiments. The effects of Aza treatment alone on the different cell lines are discussed below.
Low dose Aza shows synergistic effects with Gem and Cis in NSCLC cell lines. Two human NSCLC cell lines (A549 and HTB56) were assessed for their sensitivity to either Aza, Gem and Cis alone or in combination by MTS-proliferation assay. Combinational treatment consisted of low dose Aza (25 and $100 \mathrm{nM}$ ) combined with Gem or Cis in a wide dose range. Effects were measured after 48-h treatment and potential synergisms were calculated according to the method of Chou and Talalay. Neither A549 cells (Fig. 2A, left panel) nor HTB56 cells (Fig. 2A, right panel) showed sensitivity to Aza alone. Nevertheless, low dose Aza enhanced the activity of Gem and Cis in A549 (Fig. 2B and C) as well as the activity of Cis in HTB56 (data not shown). We observed clear synergisms [Combination index $(\mathrm{CI})<0.9$ ] in the proliferation assays for nearly every tested combination. A549 cells revealed very strong (CI <0.1) and strong synergisms (CI 0.1-0.3) for both 25 and $100 \mathrm{nM}$ Aza combined with $10-1000 \mathrm{nM}$ Cis as well as for $25 \mathrm{nM}$ Aza combined with 10-500 nM Gem. The combination of $100 \mathrm{nM}$ with 10-500 nM Gem showed slightly weaker synergism. HTB56 cells demonstrate very strong and strong synergism at combinations of $25 \mathrm{nM}$ Aza with 10-100 nM Cis and $100 \mathrm{nM}$ Aza with 10-50 nM Cis. Overall, the strength of the calculated synergism decreased with increasing doses of Cis and Gem (Fig. 2B and C). Colony formation assays reaffirmed synergistic drug interactions after 24-h treatment for 

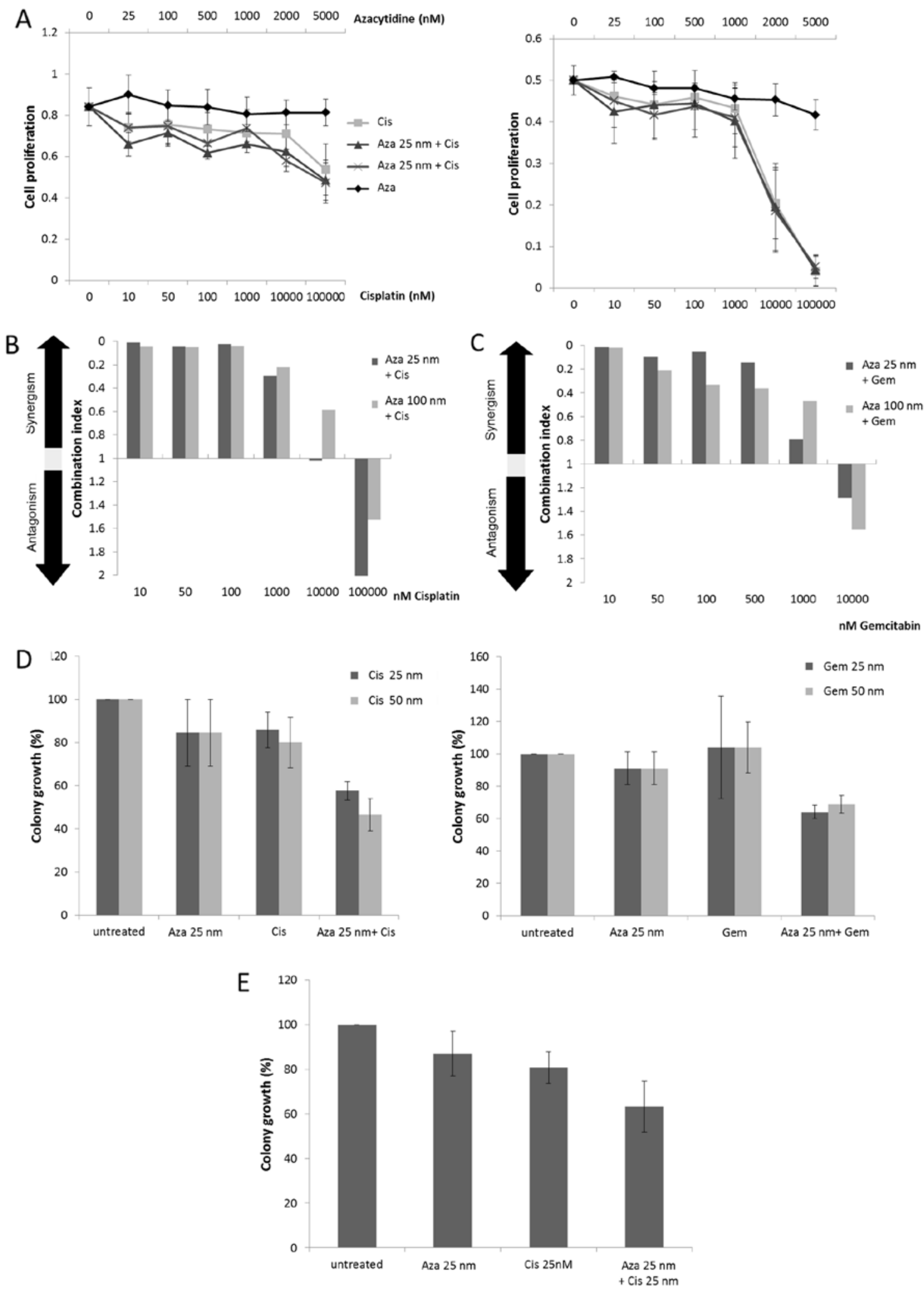

Figure 2. Low dose Aza shows synergistic effects with Gem and Cis in NSCLC cell lines. (A) After $48 \mathrm{~h}$ of treatment, the combination of $25 \mathrm{or} 100 \mathrm{nM}$ of Aza and a wide dose range of Cis showed enhanced inhibition of cell proliferation compared to single agent treatment in A549 (left panel) and HTB56 (right panel) cells. Data are shown as mean \pm standard deviation $(n=3)$. Calculation of synergism according to the method of Chou and Talalay. A combination index $(\mathrm{CI})<0.9$ indicates synergism, $>1.1$ antagonisms. Calculations were based on the means of MTS proliferation assays. Low dose Aza showed synergistic interactions with Cis in A549 cells (B). Notably, the strength of the synergism decreased with increasing Cis doses. Treatment of HTB56 cells showed similar results. Calculations are based on the means of MTS proliferation assays. Low dose azacytidine showed synergisms with Gem in a wide dose range in A549 cells (C). The strength of synergism decreased with increasing Gem doses. Results of colony formation assays are shown (D). A549 cells were treated for $24 \mathrm{~h}$ and plated in methylcellulose. A549 colonies containing $>50$ cells were quantified after 7 days of incubation. Results are shown as mean \pm standard deviation $(\mathrm{n}=3)$. Combination of $25 \mathrm{nM}$ of Aza with 25 and $50 \mathrm{nM}$ of Cis (left panel) as well as 25 and $50 \mathrm{nM}$ of Gem (right panel) indicated synergistic reduction of colony formation compared to untreated cells. (Student's t-test; $\mathrm{p}<0.05 ;{ }^{*} \mathrm{p}<0.005$ ). Results of the colony formation assays with HTB56 cells (E). The cells were treated for $24 \mathrm{~h}$ and plated in methylcellulose. Colonies containing $>50$ cells were quantified after 11 days of incubation. Results are shown as mean \pm standard deviation, $\mathrm{n}=3$. Combination of $25 \mathrm{nM}$ of Aza with $25 \mathrm{nM}$ of Cis showed synergistic reduction of colony formation. ("p $<0.05)$. 

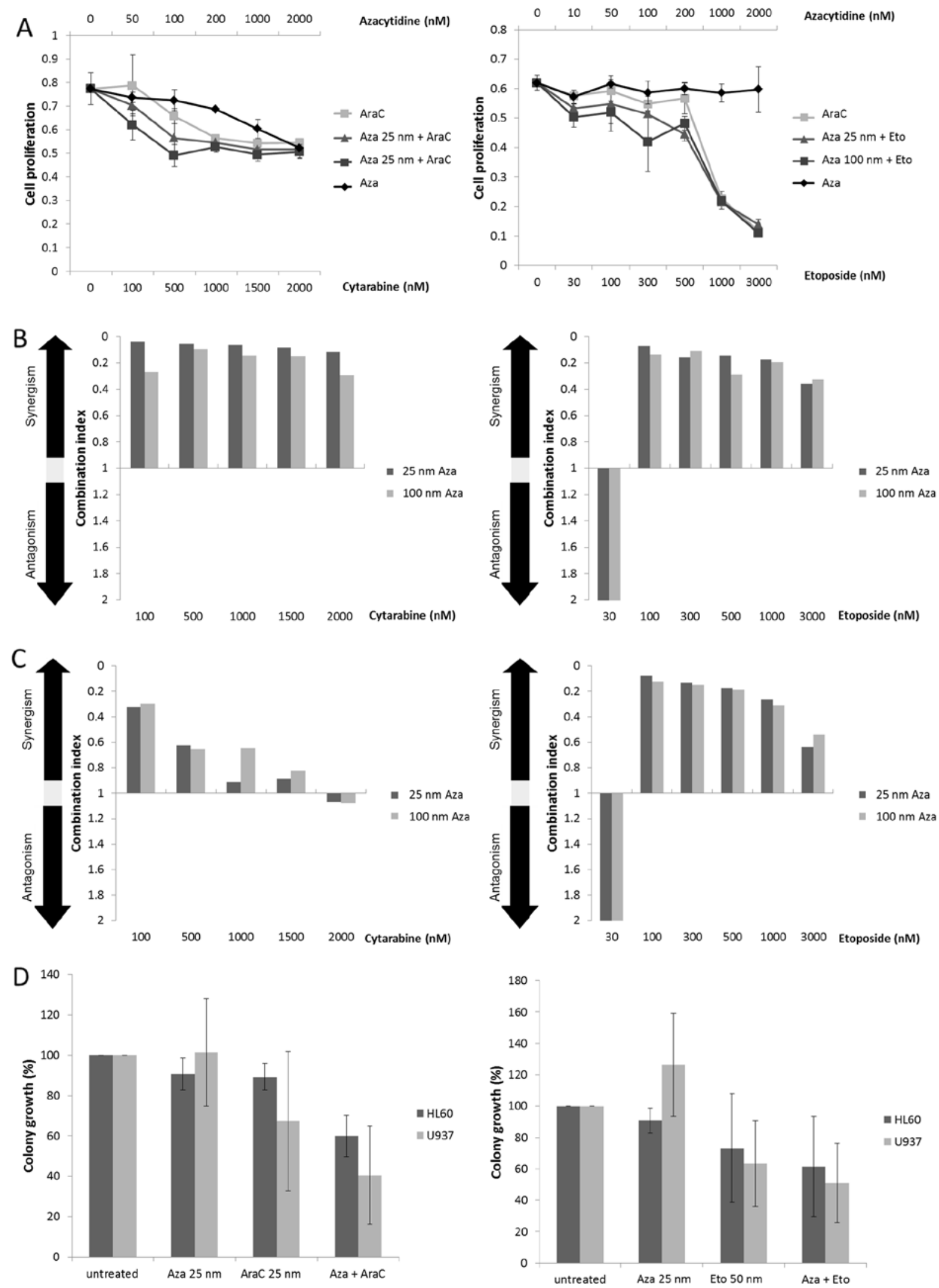

Figure 3. Low dose Aza shows synergistic effects with AraC and Eto in AML cell lines. Representative growth curve (A) for HL60 cells treated for $48 \mathrm{~h}$ with 25 and $100 \mathrm{nM}$ of Aza combined with a wide dose range of AraC (left panel) or Eto (right panel). Combination treatment showed enhanced reduction of cell proliferation compared to single agent treatment. This experiment was performed three times with similar results. (B) Calculations of synergism according to the method of Chou and Talalay. A combination index (CI) $<0.9$ indicates synergism, $>1.1$ antagonisms. Calculations are based on the means of MTS proliferation assays. Aza (25 and $100 \mathrm{nM}$ ) showed synergistic interactions with a wide dose range of AraC (left panel) as well as Eto (right panel) in HL60 cells. (C) Calculations of synergisms according to the method of Chou and Talalay. Calculations are based on the means of MTS proliferation assays. In U937 cells 25 and $100 \mathrm{nM}$ of Aza showed synergisms with a variety of AraC (left panel) and Eto (right panel) doses. The results of the colony formation assays are shown (D). HL60 and U937 cells were treated for $24 \mathrm{~h}$ with $25 \mathrm{nM}$ of Aza combined with either $25 \mathrm{nM}$ of AraC or $50 \mathrm{nM}$ of Eto and plated in methylcellulose. Colonies containing $>50$ cells were quantified after 7 days of incubation. Combination treatment indicated synergistic reduction of colony formation. 
A
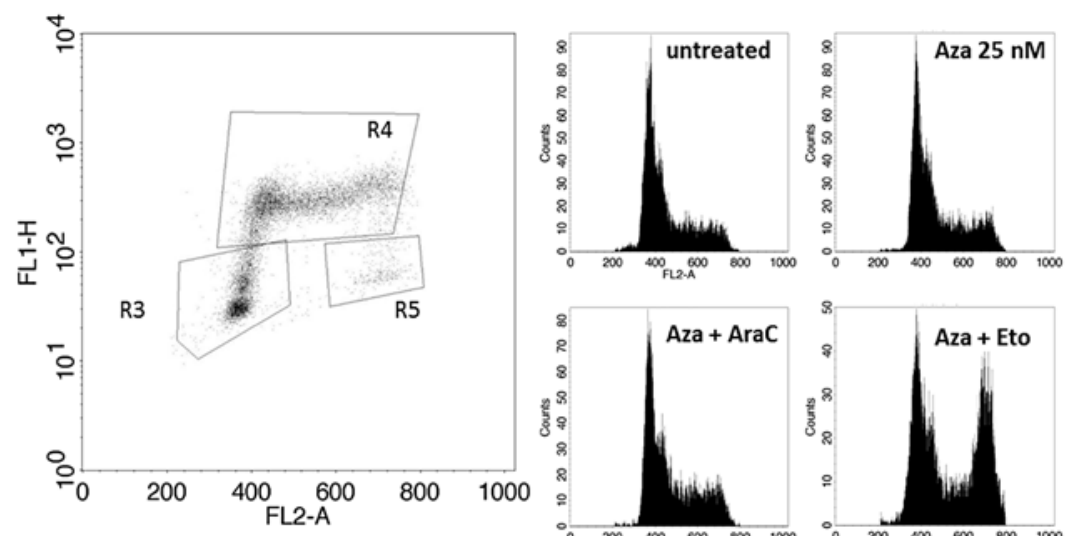

B
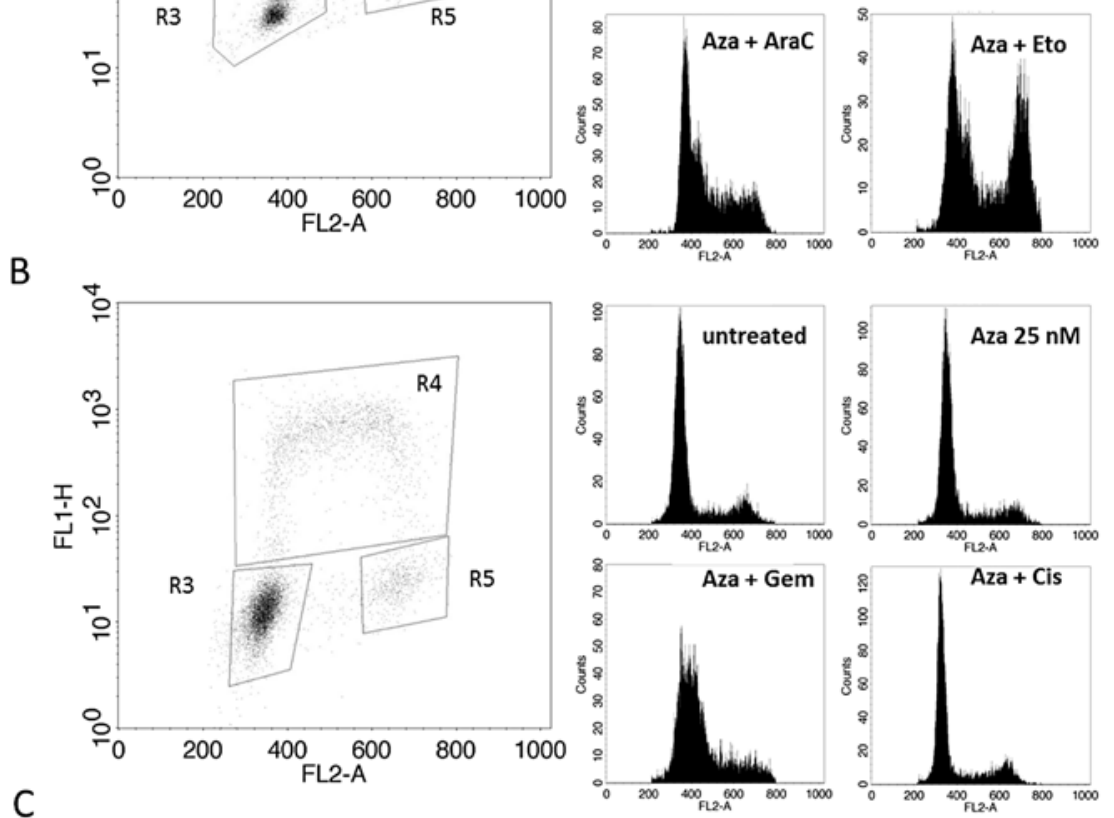

C
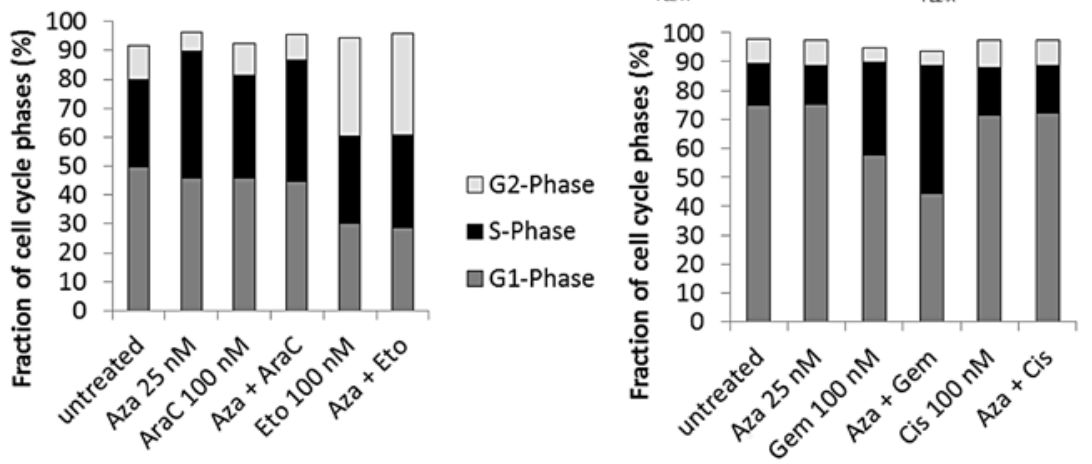

Figure 4. Low dose Aza treatment does not lead to cell cycle aberrations. The cell cycle was analysed by BrdU incorporation (A, left panel) and propidium iodide (left panel) staining followed by flow cytometry. (A) Exemplary staining for BrdU and the gating settings. Left panel, propidium iodide staining for U937 cells analyzed after 24-h treatment with $25 \mathrm{nM}$ of Aza, $100 \mathrm{nM}$ of AraC or Eto or the respective combinations. A similar approach was used for HTB56 cells (B). The cells were analyzed after 24-h treatment with $25 \mathrm{nM}$ of Aza, $100 \mathrm{nM}$ of AraC or Eto (AML) respectively $100 \mathrm{nM}$ of Cis or Gem (NSCLC) or the respective combinations. Cell cycle distribution was calculated and the summaries for HL60 (C, left) and HTB56 cells (C, right) are shown according to one representative BrdU incorporation flow cytometry analysis $(\mathrm{n}=2)$.

both cell lines (Fig. 2D and E). A549 cells indicate synergisms for the combination of $25 \mathrm{nM}$ Aza with $25 \mathrm{nM}(\mathrm{p}=0.003)$ and $50 \mathrm{nM}$ Cis $(\mathrm{p}=0.007)$ as well as with 25 and $50 \mathrm{nM} \mathrm{Gem}$ $(\mathrm{p}=0.0046$ and $\mathrm{p}=0.01)$. Clonal growth in HTB56 cells treated with $25 \mathrm{nM}$ Aza and $25 \mathrm{nM}$ Cis was synergistically reduced as well ( $p=0.03)$ (Fig. 2E).

Effects of AraC and Eto in AML cell lines are synergistically enhanced by low dose Aza. We treated two human AML cell lines (HL60 and U937) with Aza, Eto and AraC alone or with combinations of 25 or $100 \mathrm{nM}$ Aza with varying doses of either Eto or AraC. The proliferation assays revealed an enhancement of AraC and Eto activity by low dose Aza in HL60 cells (Fig. 3A) and to a lesser extent in U937 cells (data not shown). Calculation according to Chou and Talalay indicated synergistic drug interactions between these agents. In HL60 cells the combination of $25 \mathrm{nM}$ Aza with 100-2000 nM AraC resulted mainly in very strong synergisms $(\mathrm{CI}<0.1)$ whereas the combination of $100 \mathrm{nM}$ Aza with AraC revealed rather strong synergisms (CI 0.1-0.3). In U937 cells these combinations effected weaker synergism and even additive effects (CI 0.9-1.1) in higher AraC doses (Fig. 3C, left panel).

For the combination of 25 and $100 \mathrm{nM}$ with $30-3000 \mathrm{nM}$ Eto we observed a clear dose dependency in regard to the quality of synergistic interaction for both HL60 and U937 cells (Fig. 3B and C, right panel). The strength of synergism decreased with increasing doses of Eto. However, the lowest dose (30 nM Eto) constistantly showed antagonisms when 
A
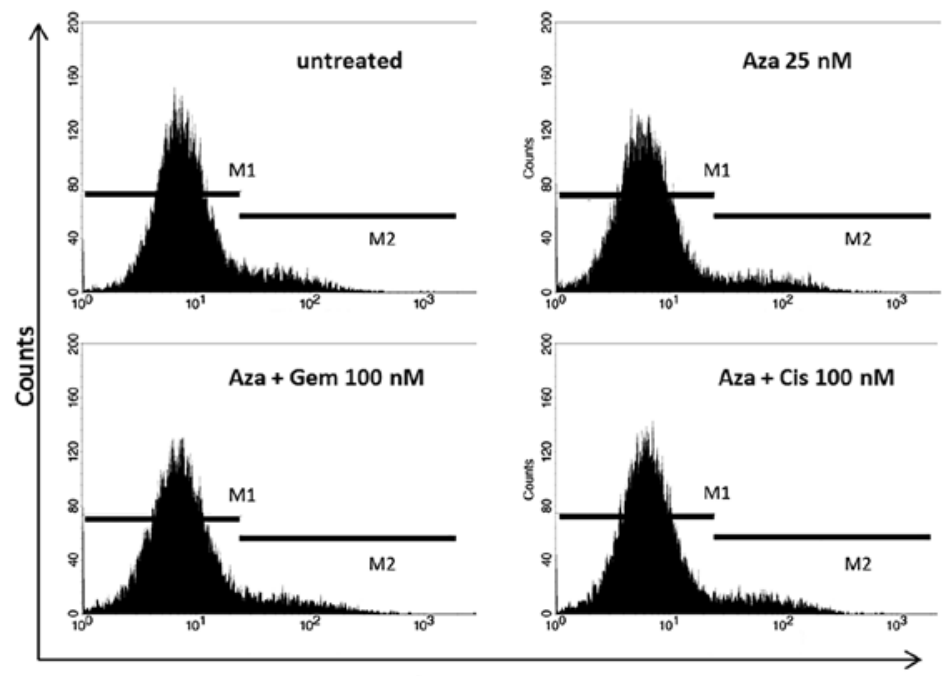

B

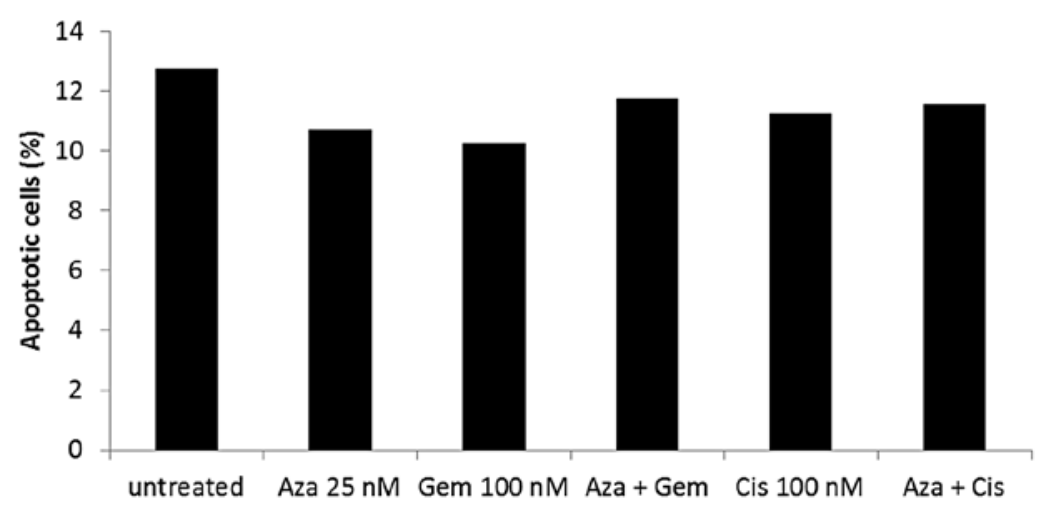

Figure 5. Low dose Aza treatment does not lead to increased apoptosis. A549 cells were analyzed after 24-h treatment with $25 \mathrm{nM}$ of Aza, $100 \mathrm{nM}$ of Cis or Gem or the respective combinations (A). Fraction of apoptotic cells was not noteably increased by any treatment (M2 region). This experiment was repeated with similar results. (B) The bar diagram summarises the obtained results. There were no major changes in apoptotic fraction. This experiment was repeated with similar results.

combined with 25 or $100 \mathrm{nM}$ Aza in both cell lines. Colony formation assays confirmed potential drug synergism after 24-h treatment. We observed a distinct reduction of clonal growth by the combination of $25 \mathrm{nM}$ Aza and $25 \mathrm{nM}$ AraC or $50 \mathrm{nM}$ Eto in both cell lines (Fig. 3D). However, although the colony formation was observably inhibited, the Eto containing combinations failed to reach statistical significance in HL60 $(\mathrm{p}=0.172)$ and $\mathrm{U} 937(\mathrm{p}=0.079)$. Treatment with $25 \mathrm{nM}$ Aza and $25 \mathrm{nM}$ AraC reached significance in HL60 cells $(\mathrm{p}=0.021)$, but not in U937 ( $\mathrm{p}=0.051)$.

Low dose Aza treatment does not affect the cell cycle nor induce increased activation of active caspase-3. To further explore possible mechanisms behind the observed synergisms we analyzed the cell cycle and the apoptosis rate by flow cytometry. HL60 and U937 cells were treated with $25 \mathrm{nM}$ Aza, $100 \mathrm{nM} \mathrm{AraC}$ and $100 \mathrm{nM}$ Eto alone and in combination for $24 \mathrm{~h}$. A549 and HTB56 cells were treated with $100 \mathrm{nM}$ Cis and $100 \mathrm{nM} \mathrm{Gem}$ along with the respective combinations. The BrdU incorporation flow cytometry revealed no consistent trend towards a specific Aza effect. Aza $(25 \mathrm{nM})$ alone did not cause any alterations compared to the untreated control in the four cell lines. We observed an increase of the G2-phase by
Aza plus Eto in both U937 (Fig. 4A) and HL60 cells (Fig. 4C, left). Aza plus Gem led to an increase of the S-phase and a shift towards early S-phase in HTB56 cells (Fig. 4B and C, right panel). The combination of Aza and AraC increased the S-phase in U937 cells as well (Fig. 4A). All alterations were consistent with the effects mediated by single treatment with Eto, $\mathrm{AraC}$ and $\mathrm{Cis}$ in the respective cell lines. However, the Gem-mediated increase of the S-phase in HTB56 cells was enhanced by the addition of Aza. The cell cycle in A549 was not altered by any treatment. The above results provide no evidence that synergistic drug interactions in Aza containing combinations might be explained by cell cycle alterations.

A549 and HTB56 were also analyzed by active caspase-3 staining after 24-h treatment (Fig. 5). We observed no constant increase in active caspase- 3 levels in either cell line by any treatment. Therefore, we found no indication of drug mediated early apoptosis via this pathway after low dose treatment.

Global methylation patterns might not be affected by $25 \mathrm{nM}$ Aza or Aza containing combinations. The DNA methyltransferase inhibitor (DNMTi) Aza leads to global DNA hypomethylation and is able to reactivate silenced tumor suppressor genes by promoter demethylation. To examine 
A
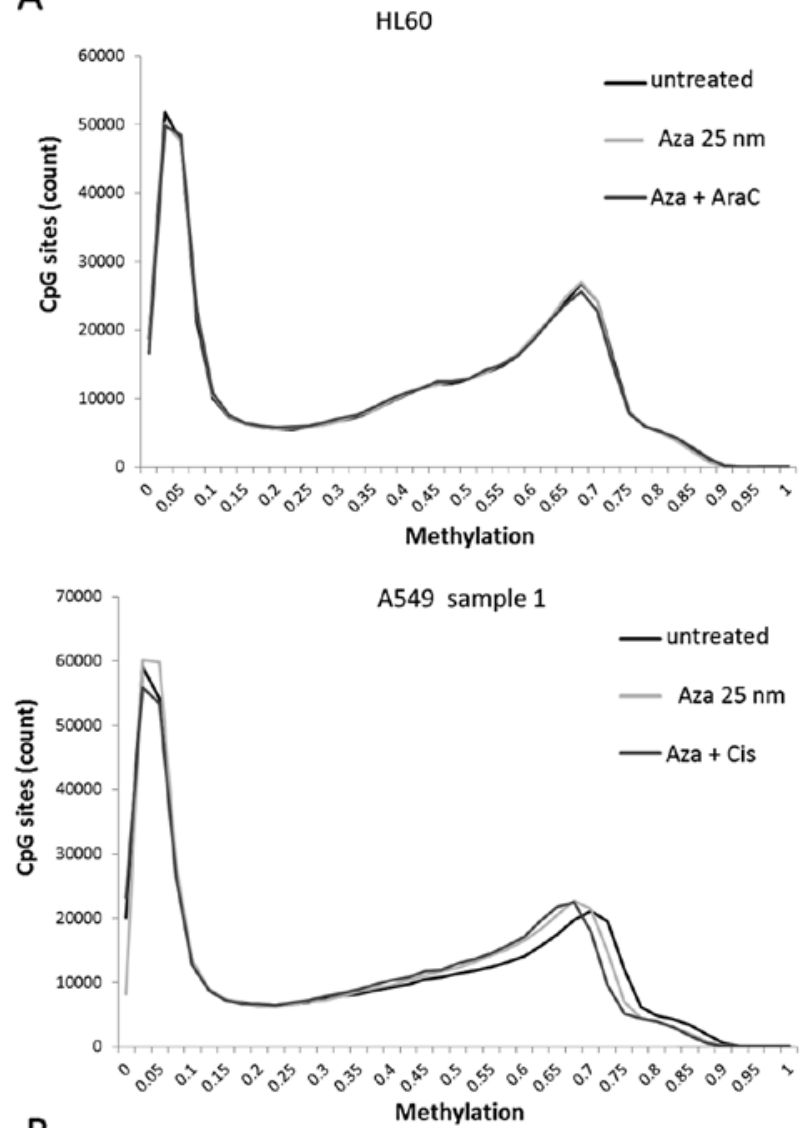

B

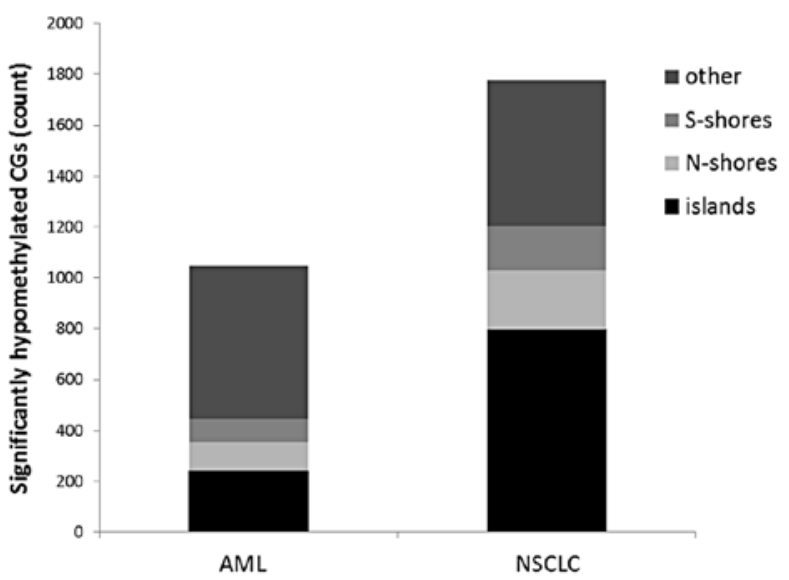

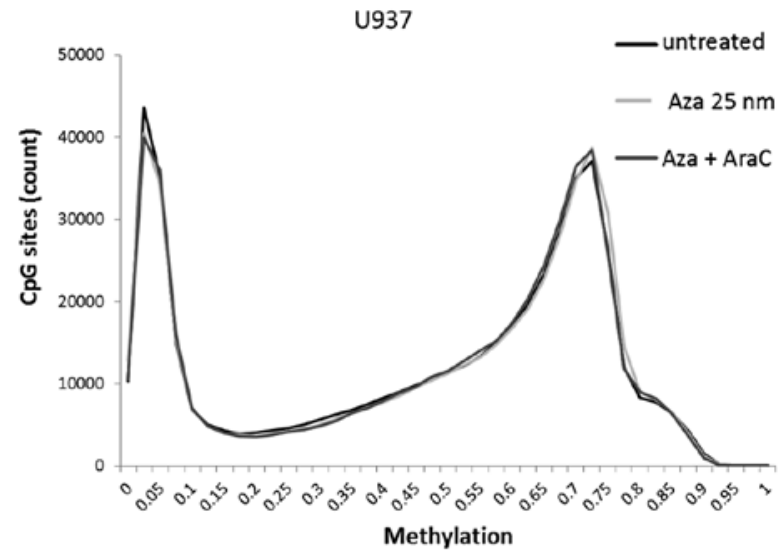
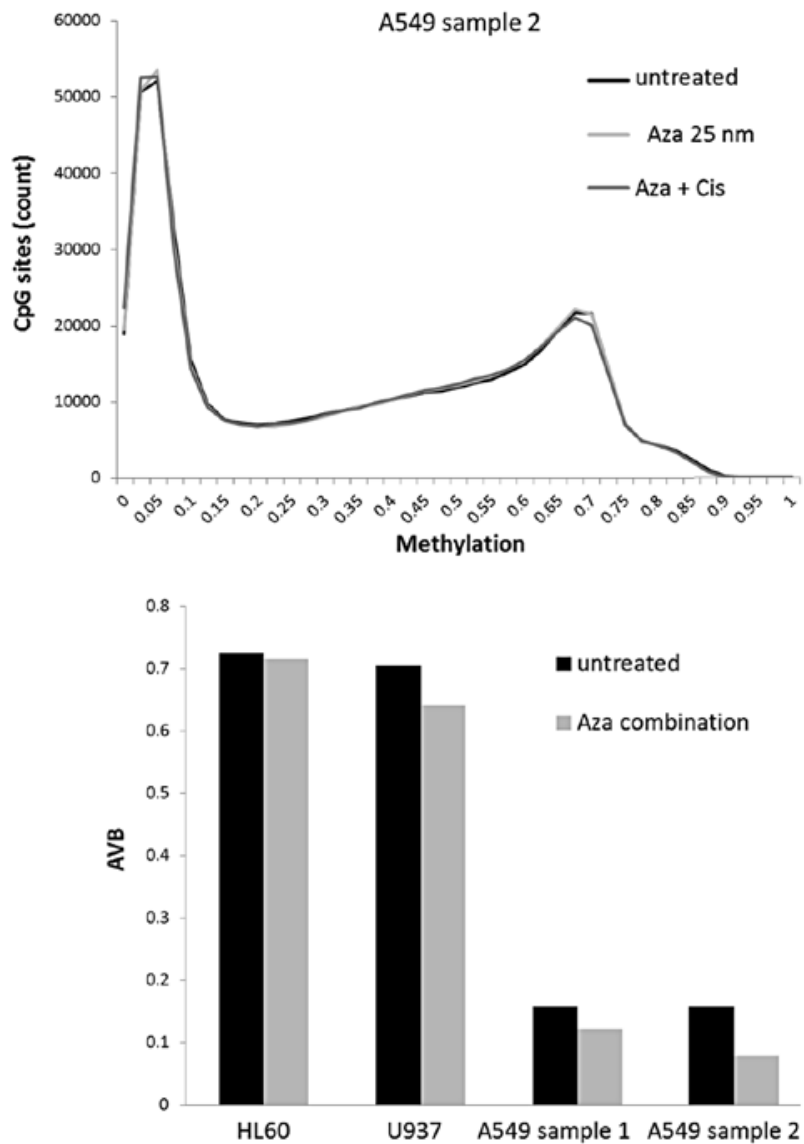

Figure 6. Methylation changes after Aza treatment. Genome-wide methylation analysis of HL60, U937 and two independent samples of A549 cells were performed by $450 \mathrm{~K}$ bead arrays after $24 \mathrm{~h}$ of treatment (A). We observed a bimodal methylation distribution in every tested cell line and after each treatment condition. AML cells (especially U937 cells) showed a higher amount of high methylated CpG sites than NSCLC cells. Aza and Aza combination treatment led to a discrete shift in DNA methylation in only one of four samples (A549 sample 1). Global DNA methylation of the other three samples was not affected. Class comparisons were performed by ArrayTools software to analyze the effects of azacytidine treatment (B). NSCLC cells showed a higher number of significantly hypomethylated CpG sites $(\mathrm{p}<0.05)$ after Aza treatment than AML cells. However, most affected CpG sites were located by the CpG islands. Bar diagram shows average beta (AVB) values for CpG sites associated with the MGMT gene. CpG sites were significantly hypomethylated $(\mathrm{p}<0.05)$ in class comparisons in both AML and NSCLC cells. Besides MGMT, we found an overlap in several other candidate tumor suppressor genes that were associated with significantly hypomethylated $\mathrm{CpG}$ sites after Aza treatment.

whether Aza induced alterations in DNA methylation might give a possible explanation for the enhancement of cytotoxic drug activity, thus we performed genome-wide methylation analysis using $450 \mathrm{~K}$ bead arrays.

Cells were treated equally to those examined in colony formation assays. We analysed HL60 and U937 cells treated with $25 \mathrm{nM}$ Aza and $25 \mathrm{nM}$ AraC and two seperate samples of
A549 cells treated with $25 \mathrm{nM}$ Aza and $25 \mathrm{nM}$ Cis alone and in combination for $24 \mathrm{~h}$.

The methylation analysis revealed a bimodal methylation distribution with a low methylation peak ranging from average beta (AVB) values 0 to 0.15 and a high-methylation peak ranging from AVB values 0.55 to 0.8 in every tested cell line (Fig. 6A). In both A549 samples the low-methylation 
A

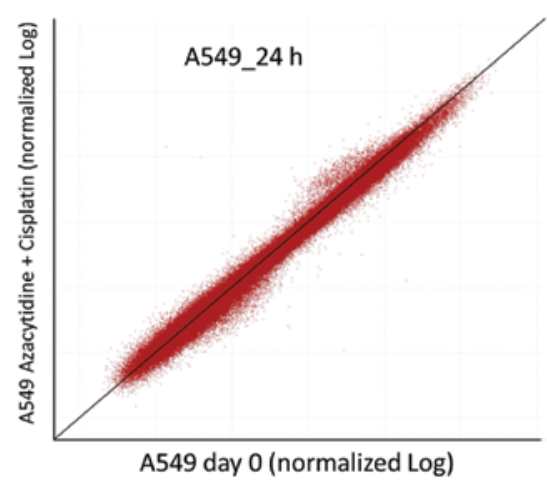

B

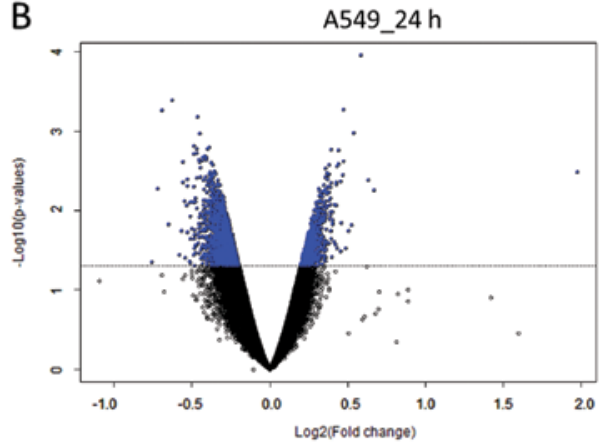

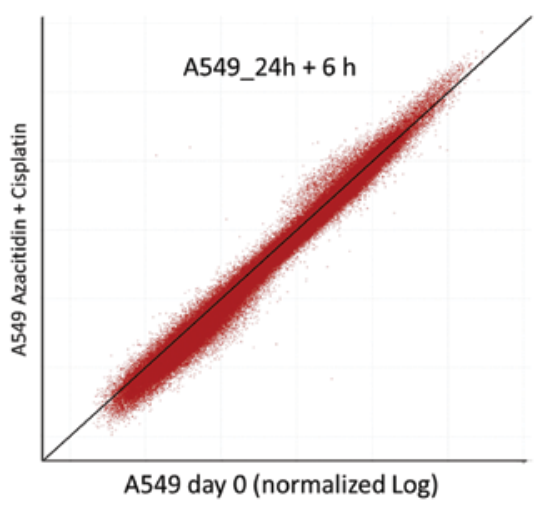

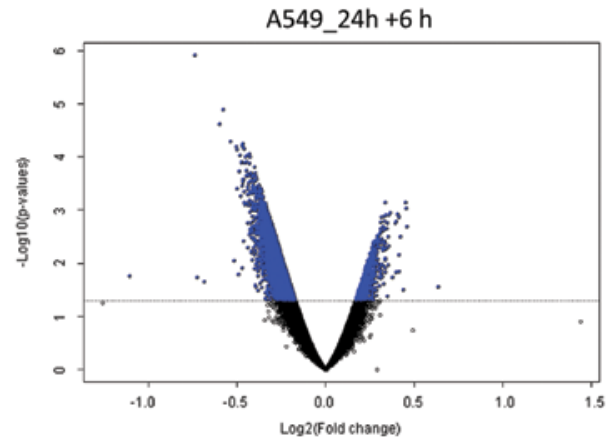

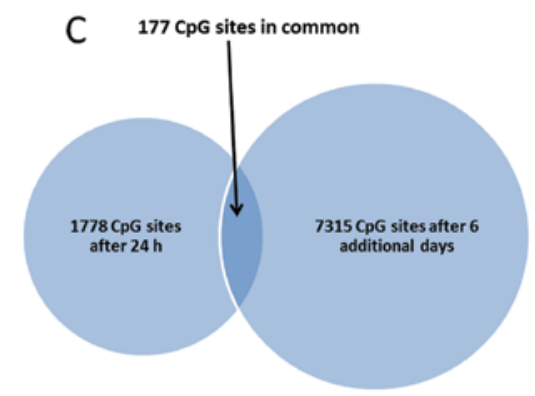

Figure 7. Aza DNA demethylation increases time-dependently. Scatterplots of DNA methylation levels (A) for A549 cells treated with Aza and Cis for 24 h (left panel) and A549 cells that were recultured for 6 additional days in drug-free medium after $24 \mathrm{~h}$ of treatment (right panel). Data under the diagonal line represent $\mathrm{CpG}$ sites that showed lower methylation values in contrast to A549 cells at experiment day 0 . Additional incubation time led to an increase of hypomethylated $\mathrm{CpG}$ sites especially in the low-methylation group. Volcano Plots of DNA methylation levels (B) for A549 cells treated for 24 h (left panel) or after 24-h treatment followed by additional 6 days of incubation (right panel). A log 2 fold-change $<0$ represents hypomethylated, $>0$ hypermethylated CpG sites. Colors represent the significance of methylation changes ranging from blue (significant) to black (not significant). The additional incubation led to a $4.1-$ fold increase of significantly hypomethylated CpG sites. Methylation changes showed only slight variance. (C) Venn diagram of significantly hypomethylated CpG sites in A549 cells after 24-h treatment and 24-h treatment with additional 6 days of incubation in drug free medium. We observed an overlap over 177 CpG sites that were hypomethylated in both samples.

peak contained 38.6-39.2\% and the high-methylation peak contained 31.1-32.2\% of all CGs. The AML cell lines showed a higher methylation level with a low-methylation peak including 24.8-33.6\% and a high-methylation peak including $37.3-48.7 \%$ of all CGs. In the histograms, we observed no shift of these peaks, except for the A549 cells (sample 1). In the present study, the treatment with $25 \mathrm{nM}$ Aza caused a discrete shift to lower methylation values which was slightly enhanced by the addition of Cis.

We performed class comparisons to further evaluate drug induced methylation changes. Our analysis revealed 1,046 significant hypomethylated $(\mathrm{p}<0.05) \mathrm{CGs}$ in AML and 1,778 significant hypomethylated $(\mathrm{p}<0.05)$ CGs in NSCLC cell lines after Aza and Aza combination treatment. Only 240 of 1,046 CGs in AML and 798 of 1,778 CGs in NSCLC cells were found on islands (Fig. 6B, left panel). Several of these CGs were associated with candidate tumor suppressor genes, e.g. MGMT, THRB, L3MBTL4, EDNRB, CDH13 and TGFBR3. However, the CGs associated with these genes were methylated in untreated AML cells but already hypomethylated in NSCLC cells as shown for MGMT (Fig. 6B, right panel).

Low dose Aza induced CG-demethylation increases in a timedependent manner. To identify long-term effects of Aza and cytotoxic drugs on DNA methylation patterns, we split some of the A549 cells (samples 1 and 2) after the 24-h treatment for bead array analysis and recultured them in Aza and Cis-free medium. After 6 days of incubation we isolated the DNA and performed $450 \mathrm{~K}$ bead arrays.

We compared the effects of Aza plus Cis combination treatment after $24 \mathrm{~h}$ and after the 6-day incubation. The scatterplots showed a shift especially of the low methylated CGs 
to lower AVB values after the additional 6 days. However, the already high methylated CGs shifted to even higher AVB values (Fig. 7A).

In class comparisons we found 7315 CGs significantly hypomethylated $(\mathrm{p}<0.05)$ after Aza and Aza combinational treatment with a 4.1-fold increase compared to analysis after 24-h treatment. We further compared the DNA methylation of untreated and combined treated cells with DNA isolated before the 24-h treatment and found a significantly higher number of at least $10 \%$ demethylated CGs after Aza plus Cis treatment compared to the untreated cells (sample 1, 958-308 CGs; sample 2, 66-40 CGs, Fisher's exact test: p=0.035). The volcano plots also revealed an increase in the number of significantly demethylated CGs through Aza containing treatment. We observed only minor scattering in methylation deviation (Fig. 7B).

To evaluate the consistency of the Aza induced hypomethylation between these two time periods of measurement, we compared the lists of significant hypomethylated CGs. Our findings resulted in an overlap of over 177 CGs indicating that $10 \%$ of the CGs being hypomethylated after 24 -h treatment remain hypomethylated after the longer incubation times (Fig. 7C). We also correlated the significant hypomethylated CGs with their corresponding genes and found 1,238 and 4,078 genes being affected by at least one hypomethylated CG after 24-h treatment and the following 6-day incubation. A comparison of these genes exposed an overlap of over 564 genes, so that nearly $45 \%$ of all genes that were affected by at least one CG after 24-h treatment remained affected after 6 days of incubation.

\section{Discussion}

Epigenetic agents might enhance cytotoxic drug antitumor activity. In the present study we observed strong synergisms according to the calculation by Chou and Talalay (22) between low dose Aza and AraC or Eto in AML, respectively, Cis and Gem in NSCLC cell lines. These synergisms showed consistency over a high dose range and different cell lines. Our findings go along with earlier studies that indicate synergistic interactions between Aza and Cis in multiple cancer types (23-25). Furthermore, different studies describe increases in sensitivity to AraC or Eto when combined with DNMT inhibitory drugs Aza and decitabine (26-28). In comparison to these studies we used much lower doses ( $25 \mathrm{nM} \mathrm{Aza)}$ and a shorter treatment time ( $24 \mathrm{~h}$ ) but nevertheless observed distinct effects. These low drug concentrations neither altered the cell cycle nor increased the rate of apoptosis measured by active caspase-3 staining. Potential synergisms between Aza and Gem have not been explored previously.

In this study, treatment with Aza alone revealed only discrete effects on cell proliferation. The maximal doses of $2 \mu \mathrm{M}$ in AML and $5 \mu \mathrm{M}$ in NSCLC cell lines decreased cell proliferation in MTS assays by $<17 \%$ after 48 -h treatment. A549 cells even appeared to be completely insensitive to Aza. These marginal effects on cell proliferation by doses below $2 \mu \mathrm{M}$ are consistent with the findings of Hollenbach et al (15) and Murakami et al (29) who described a reduced cell viability at concentrations $\geq 1 \mu \mathrm{M}$ respectively
$>2 \mu \mathrm{M}$ in four different AML cell lines. Remarkably, colony formation was clearly reduced by the very low dose of $25 \mathrm{nM}$ of Aza for $24 \mathrm{~h}$ in three of four cell lines. This decrease of $>10 \%$ is comparable to the inhibition of colony formation induced by $25 \mathrm{nM}$ AraC, $25 \mathrm{nM}$ and $50 \mathrm{nM}$ cisplatin and even stronger than the effect of $25 \mathrm{nM}$ gemcitabine. It is possible, that the seven days of incubation following the $24 \mathrm{~h}$ of treatment might enhance epigenetic Aza effects that result in the observed reduction in colony formation. Additionally, in colony formation assays the cells are not able to create their preferred milieu of growth factors and other stimuli (in contrast to cell suspensions) and therefore might be more vulnerable to the applied drugs (30).

Using higher Aza doses, many authors describe a dosedependent induction of apoptosis $(29,31)$ and cell cycle aberrations. Hollenbach et al (15) observed an increase of the sub-G1-fraction, while Hagemann et al (18) described an increase of the $\mathrm{S}$ phase after doses below $10 \mu \mathrm{M}$, respectively a G2 phase arrest for doses $\sim 10 \mu \mathrm{M}$ Aza. As we found synergistic inhibition of cell proliferation and colony formation after treatment with very low doses of Aza, Cis, AraC, Eto and Gem, we focused on the effects of these low drug concentrations in search for the mechanisms of synergism. In contrast to higher doses, treatment with the respective low doses neither altered the cell cycle nor increased the rate of apoptosis measured by active caspase- 3 staining in any way that could be correlated with synergistic interaction.

An important question in regard to combination treatment is the form of drug application schedule. We hypothesize that Aza as an epigenetic agent might be able to sensitize cells for cytotoxic drugs. As epigenetic effects such as demethylation show time-dependence (31), it seems likely that cytotoxic drug activity might be enhanced rather by epigenetic pretreatment than simultaneous epigenetic-cytotoxic therapy. Accordingly, many authors preferred sequential drug application schedules (25-27,32). Nevertheless, Quin et al (33) described synergistic interactions between decitabine and AraC in both simultaneous and sequential treatment. In the present study we observed no difference in antitumor effectiveness between simultaneous and sequential Aza combination treatment with all four cytotoxic drugs. Therefore, we chose the simultaneous application for our further experiments.

There are several possible explanations for the observed synergisms between Aza and cytotoxic agents. Aza is able to reactivate silenced tumor suppressor genes by promoter CpG-demethylation (34). As this is the case, it is a rational hypothesis that synergistic drug-drug interactions might be based on reactivated tumor suppressor and/or chemo sensitivity genes that make cells more vulnerable for cytotoxic treatment. Accordingly, Plumb et al (35) described that pretreatment with decitabine sensitized ovarian carcinoma cells to subsequent cisplatin treatment, most likely due to MLH-1 reactivation. DNMT inhibitory druginduced promoter demethylation does not necessarily lead to increased gene transcription, but can affect decreased expression (20,36). Efferth et al (26) observed that MDR-1 overexpressing leukemic cells were sensitized to several cytotoxic drugs after Aza treatment. Even though Aza led to a massive MDR1 promoter demethylation, gene expression was rather decreased than increased. Additionally, 
Kong et al (27) described in an early study that Aza treatment increased the activity of 2'-deoxycytidine kinase (dCK) in dCK-deficient HL60 cells and therefore partially reversed the resistance to AraC. In the present study, we used a very low dose of Aza over a short incubation time. Consequently, we found only a relatively small number of significantly hypomethylated CG sites. We found only a small overlap of CG sites that are significantly hypomethylated in AML and NSCLC cells. Besides, we observed a greater overlap of genes in AML and NSCLC that are associated with significantly hypomethylated CG sites and that might indicate the existance of several target genes. Some of these genes include candidate tumor suppressor genes like MGMT $(37,38)$, THRB (39,40), L3MBTL4 (41), EDNRB (42), CDH13 (43) and TGFBR3 (44).

Aza treatment leads to genome-wide demethylation and therefore alters the epigenetic landscape. Demethylation appears preferentially at former high methylated CG sites and results in a shift of the bimodal methylation distribution of the cell; the high-methylation peak shifts to lower AVB values (18). Global hypomethylation appears to be causally linked to chromosomal instability $(45,46)$ and might enhance cytotoxic drug activity, probably by DNA damage-mediated apoptosis (31). Accordingly, Quin et al (33) described that apoptotic cells showed hypomethylation compared to nonapoptotic cells after combination treatment with decitabine and AraC. Thus, hypomethylation might sensitize cells to AraC treatment. Hascher et al (19) also hypothesize that Aza might act rather by change of the global epigenome than by reactivation of single tumor-suppressor genes. This idea is supported by the fact that Aza induces a specific and reproducable methylation pattern, that seems to be dominant over cell line-specific methylation patterns $(19,20)$. Additionally, although genes regulated by Aza and decitabine only show slight overlap $(15,20)$, both agents act synergistically with several cytotoxic drugs, e.g. cisplatin (23-25,47). These data suggest that there might be other or additional underlying mechanisms than specific promoter CG demethylation. In the present study, we only observed small changes in methylation patterns due to the very low dose of Aza. A shift of the bimodal methylation distribution was found in one of four cell lines. Additional incubation time after the 24-h treatment did not lead to major changes in DNA methylation distribution, but resulted in a 4.1-fold increase of significantly hypomethylated CpG sites in A549 cells. Nearly $10 \%$ of those $\mathrm{CpG}$ sites that were significantly hypomethylated after $24 \mathrm{~h}$ maintaining significantly hypomethylated after the extended treatment schedule (177/1778 CpG sites). These data indicate certain consistency as well as time-dependence of low dose 5-azacytidine induced methylation changes. Although we only found minor DNA methylation changes, we observed distinct synergistic activity which raises the question whether these minimal changes in methylation already make the cells more susceptible for cytotoxic agents, or whether there are further mechanisms independent of methylation.

Aza is incorporated to a much greater extent into RNA than into DNA (15). This distribution suggests that the RNA-incorporation might also be involved in synergistic Aza interactions. The enzyme ribonucleotide reductase (RNR) plays a key role in DNA synthesis, cell growth and DNA repair (48). The catalytic M2-subunit (RRM2) is significant for the enzymatic function (48) and appears to be frequently overexpressed in malignant cells $(49,50)$. Its overexpression leads to the typically increased DNA synthesis in tumors and mediates resistance against nucleoside analoga (51). Aimiuwu et al (52) observed that Aza treatment attenuated RRM2 mRNA as well as total RNA stability and resulted in reduced RNR protein expression. A decrease of RNR activity downregulates the cell's stock of desoxyribonucleoside triphosphates (48) and therefore, might increase the incorporation of nucleoside analogs like AraC and gemcitabine. Additionally, Rauscher et al (53) described in an earlier study that RNR inhibition enhances AraC activity. Increased incorporation of nucleoside analogs based on Aza mediated RNR inhibition might be a mechanism for synergistic drug interaction. Furthermore, nucleoside analogs decrease RNR activity themselves by allosteric inhibition of the M2-subunit $(48,54)$. Cis interferes with the M1 subunit and therefore inhibits RNR activity as well (55). Additional inhibition on the RNA level might potentiate the suppression of RNR activity by AraC, gemcitabine and cisplatin. Earlier studies also indicate that synergistic interactions between cisplatin and DNMT inhibitors might be based on methylation-independent mechanisms $(32,56)$. These data suggest that there might be other or additional mechanisms besides DNA hypomethylation enhancing cytotoxic drug activity.

In conclusion, in the present study, we found that Aza is a promising agent for combinational anticancer drug therapy. We used very low Aza concentrations to exclude its cytotoxic activity but concentrated on its potential as an epigenetic agent. We analyzed drug interaction between Aza and four other cytotoxic drugs of different modes of action in four different cell lines and observed synergistic reduced cell proliferation and colony formation. In search for the underlying mechanisms, we found neither increased apoptosis nor cell cycle alterations. $450 \mathrm{~K}$ bead arrays revealed only few changes in global methylation but nevertheless several CG-sites that were significantly hypomethylated after Aza treatment. The number of significantly hypomethylated CG-sites increased time-dependently. Thus, although formally only observing a correlation between synergistic effects of low-dose Aza with the cytotoxic activity of various anticancer drugs and its demethylizing activity at low doses, a causal relationship between the demethylizing effects of Aza and this synergy is a valid hypothesis to be further studied preclinically and clinically.

The results of the present study could have relevance for the design of new drug combinations for AML or NSCLC therapy. Especially the observed synergistic interactions between Aza and gemcitabine as well as cisplatin in addition to the wellknown synergisms between gemcitabine and cisplatin (57) indicate that a triple combination of these agents might be of clinical interest in NSCLC therapy.

\section{Acknowledgements}

The present study was supported by the German Ministry for Education and Science (grant no. BMBF 01GS0873), the 'Deutsche Forschungsgemeinschaft' (grant no. DFG MU 1328/9-1) and the 'Deutsche Krebshilfe' (grant no. 110262). 


\section{References}

1. SEER cancer statistics review (CSR) 1975-2010 [Internet].; June 14th 2013; cited March 6th 2014]. Available from: http://seer. cancer.gov/statfacts/.

2. Jones PA and Baylin SB: The fundamental role of epigenetic events in cancer. Nat Rev Genet 3: 415-428, 2002.

3. Baylin SB and Herman JG: DNA hypermethylation in tumorigenesis: epigenetics joins genetics. Trends Genet 16: 168-174, 2000.

4. Jones PA and Baylin SB: The epigenomics of cancer. Cell 128: 683-692, 2007.

5. Gama-Sosa MA, Slagel VA, Trewyn RW, Oxenhandler R, Kuo KC, Gehrke CW and Ehrlich M: The 5-methylcytosine content of DNA from human tumors. Nucleic Acids Res 11: 6883-6894, 1983.

6. Herman JG, Merlo A, Mao L, et al: Inactivation of the CDKN2/ p16/MTS1 gene is frequently associated with aberrant DNA methylation in all common human cancers. Cancer Res 55 4525-4530, 1995.

7. Esteller M: Epigenetics in cancer. N Engl J Med 358: 1148-1159, 2008.

8. Herman JG and Baylin SB: Gene silencing in cancer in association with promoter hypermethylation. N Engl J Med 349: 2042-2054, 2003.

9. Pradhan S, Bacolla A, Wells RD and Roberts RJ: Recombinant human DNA (cytosine-5) methyltransferase. I. expression, purification, and comparison of de novo and maintenance methylation. J Biol Chem 274: 33002-33010, 1999.

10. Bird A: DNA methylation patterns and epigenetic memory Genes Dev 16: 6-21, 2002.

11. Okano M, Xie S and Li E: Cloning and characterization of a family of novel mammalian DNA (cytosine-5) methyltransferases. Nat Genet 19: 219-220, 1998.

12. Okano M, Bell DW, Haber DA and Li E: DNA methyltransferases Dnmt3a and Dnmt3b are essential for de novo methylation and mammalian development. Cell 99: 247-257, 1999.

13. Ehrlich M: DNA hypomethylation in cancer cells. Epigenomics 1: 239-259, 2009.

14. Damiani LA, Yingling CM, Leng S, Romo PE, Nakamura J and Belinsky SA: Carcinogen-induced gene promoter hypermethylation is mediated by DNMT1 and causal for transformation of immortalized bronchial epithelial cells. Cancer Res 68: 9005-9014, 2008.

15. Hollenbach PW, Nguyen AN, Brady H, et al: A comparison of azacitidine and decitabine activities in acute myeloid leukemia cell lines. PLoS One 5: e9001, 2010.

16. Cihak A: Biological effects of 5-azacytidine in eukaryotes. Oncology 30: 405-422, 1974.

17. Tsai HC, Li H, Van Neste L, et al: Transient low doses of DNA-demethylating agents exert durable antitumor effects on hematological and epithelial tumor cells. Cancer Cell 21: 430-446, 2012

18. Hagemann S, Heil O, Lyko F and Brueckner B: Azacytidine and decitabine induce gene-specific and non-random DNA demethylation in human cancer cell lines. PLoS One 6: e17388, 2011.

19. Hascher A, Haase AK, Hebestreit K, et al: DNA methyltransferase inhibition reverses epigenetically embedded phenotypes in lung cancer preferentially affecting polycomb target genes. Clin Cancer Res 20: 814-812, 2014.

20. Flotho C, Claus R, Batz C, et al: The DNA methyltransferase inhibitors azacitidine, decitabine and zebularine exert differential effects on cancer gene expression in acute myeloid leukemia cells. Leukemia 23: 1019-1028, 2009.

21. Vidaza: EPAR - product information (Internet); January 3, 2014; cited February 6, 2014. http://www.ema.europa.eu/docs/en_GB/ document library/EPAR - Product_Information/human/000978/ WC500050239.pdf.

22. Chou TC and Talalay P: Quantitative analysis of dose-effect relationships: the combined effects of multiple drugs or enzyme inhibitors. Adv Enzyme Regul 22: 27-55, 1984.

23. Festuccia C, Gravina GL, D'Alessandro AM, et al: Azacitidine improves antitumor effects of docetaxel and cisplatin in aggressive prostate cancer models. Endocr Relat Cancer 16: 401-413, 2009.

24. Tikoo K, Ali IY, Gupta J and Gupta C: 5-azacytidine prevents cisplatin induced nephrotoxicity and potentiates anticancer activity of cisplatin by involving inhibition of metallothionein, pAKT and DNMT1 expression in chemical induced cancer rats. Toxicol Lett 191: 158-166, 2009.
25. Francia G, Green SK, Bocci G, et al: Down-regulation of DNA mismatch repair proteins in human and murine tumor spheroids: implications for multicellular resistance to alkylating agents. Mol Cancer Ther 4: 1484-1494, 2005.

26. Efferth T, Futscher BW and Osieka R: 5-azacytidine modulates the response of sensitive and multidrug-resistant K562 leukemic cells to cytostatic drugs. Blood Cells Mol Dis 27: 637-648, 2001.

27. Kong XB, Tong WP and Chou TC: Induction of deoxycytidine kinase by 5-azacytidine in an HL-60 cell line resistant to arabinosylcytosine. Mol Pharmacol 39: 250-257, 1991.

28. Asano T, Nakamura K, Fujii H, et al: Altered expression of topoisomerase IIalpha contributes to cross-resistant to etoposide K562/MX2 cell line by aberrant methylation. Br J Cancer 92: 1486-1492, 2005

29. Murakami T, Li X, Gong J, Bhatia U, Traganos F and Darzynkiewicz Z: Induction of apoptosis by 5-azacytidine: drug concentration-dependent differences in cell cycle specificity. Cancer Res 55: 3093-3098, 1995.

30. Cross M and Dexter TM: Growth factors in development, transformation, and tumorigenesis. Cell 64: 271-280, 1991.

31. Khan R, Schmidt-Mende J, Karimi M, et al: Hypomethylation and apoptosis in 5-azacytidine-treated myeloid cells. Exp Hematol 36: 149-157, 2008.

32. Abbruzzese JL and Frost P: Studies on the mechanism of the synergistic interaction between 2'-deoxy-5-azacytidine and cisplatin. Cancer Chemother Pharmacol 30: 31-36, 1992.

33. Qin T, Youssef EM, Jelinek J, Chen R, Yang AS, Garcia-Manero G and Issa JP: Effect of AraC and decitabine in combination in human leukemic cell lines. Clin Cancer Res 13: 4225-4232, 2007.

34. Issa JP and Kantarjian HM: Targeting DNA methylation. Clin Cancer Res 15: 3938-3946, 2009.

35. Plumb JA, Strathdee G, Sludden J, Kaye SB and Brown R: Reversal of drug resistance in human tumor xenografts by 2'-deoxy-5-azacytidine-induced demethylation of the hMLH1 gene promoter. Cancer Res 60: 6039-6044, 2000.

36. Gius D, Cui H, Bradbury CM, et al: Distinct effects on gene expression of chemical and genetic manipulation of the cancer epigenome revealed by a multimodality approach. Cancer Cell 6: 361-371, 2004

37. Gu C, Lu J, Cui T, et al: Association between MGMT promoter methylation and non-small cell lung cancer: a meta-analysis. PLoS One 8: e72633, 2013.

38. Su Y, Xu H, Xu Y, Yu J, Xian Y and Luo Q: Azacytidine inhibits the proliferation of human promyelocytic leukemia cells (HL60) by demethylation of MGMT, DAPK and p16 genes. Hematology 17: 41-46, 2012

39. Dmitriev AA, Kashuba VI, Haraldson K, et al: Genetic and epigenetic analysis of non-small cell lung cancer with NotImicroarrays. Epigenetics 7: 502-513, 2012.

40. Dunwell TL, Hesson LB, Pavlova T, et al: Epigenetic analysis of childhood acute lymphoblastic leukemia. Epigenetics 4: 185-193, 2009.

41. Addou-Klouche L, Adelaide J, Finetti P, et al: Loss, mutation and deregulation of L3MBTL4 in breast cancers. Mol Cancer 9: 213. doi: 10.1186/1476-4598-9-213.

42. Chen SC, Lin CY, Chen YH, et al: Aberrant promoter methylation of EDNRB in lung cancer in Taiwan. Oncol Rep 15: 167-172, 2006.

43. Toyooka KO, Toyooka S, Virmani AK, et al: Loss of expression and aberrant methylation of the $\mathrm{CDH} 13$ (H-cadherin) gene in breast and lung carcinomas. Cancer Res 61: 4556-4560, 2001

44. Finger EC, Turley RS, Dong M, How T, Fields TA and Blobe GC: TbetaRIII suppresses non-small cell lung cancer invasiveness and tumorigenicity. Carcinogenesis 29: 528-535, 2008.

45. Deng G, Nguyen A, Tanaka H, et al: Regional hypermethylation and global hypomethylation are associated with altered chromatin conformation and histone acetylation in colorectal cancer. Int J Cancer 118: 2999-3005, 2006.

46. Ehrlich M: DNA methylation in cancer: too much, but also too little. Oncogene 21: 5400-5413, 2002.

47. Shang D, Liu Y, Matsui Y, Ito N, Nishiyama H, Kamoto T and Ogawa O: Demethylating agent 5-aza-2'-deoxycytidine enhances susceptibility of bladder transitional cell carcinoma to cisplatin. Urology 71: 1220-1225, 2008.

48. Eklund H, Uhlin U, Farnegardh M, Logan DT and Nordlund P: Structure and function of the radical enzyme ribonucleotide reductase. Prog Biophys Mol Biol 77: 177-268, 2001.

49. Lu AG, Feng H, Wang PX, Han DP, Chen XH and Zheng MH: Emerging roles of the ribonucleotide reductase $\mathrm{M} 2$ in colorectal cancer and ultraviolet-induced DNA damage repair. World J Gastroenterol 18: 4704-4713, 2012. 
50. Morikawa T, Hino R, Uozaki H, et al: Expression of ribonucleotide reductase M2 subunit in gastric cancer and effects of RRM2 inhibition in vitro. Hum Pathol 41: 1742-1748, 2010.

51. Klisovic RB, Blum W, Wei X, et al: Phase I study of GTI-2040, an antisense to ribonucleotide reductase, in combination with high-dose cytarabine in patients with acute myeloid leukemia. Clin Cancer Res 14: 3889-3895, 2008.

52. Aimiuwu J, Wang H, Chen P, et al: RNA-dependent inhibition of ribonucleotide reductase is a major pathway for 5-azacytidine activity in acute myeloid leukemia. Blood 119: 5229-5238, 2012.

53. Rauscher F III and Cadman E: Biochemical and cytokinetic modulation of L1210 and HL-60 cells by hydroxyurea and effect on 1-beta-D-arabinofuranosylcytosine metabolism and cytotoxicity. Cancer Res 43: 2688-2693, 1983.
54. Gray SG, Baird AM, O'Kelly F, et al: Gemcitabine reactivates epigenetically silenced genes and functions as a DNA methyltransferase inhibitor. Int J Mol Med 30: 1505-1511, 2012.

55. Smith SL and Douglas KT: Stereoselective, strong inhibition of ribonucleotide reductase from $E$. coli by cisplatin. Biochem Biophys Res Commun 162: 715-723, 1989.

56. Ellerhorst JA, Frost P, Abbruzzese JL, Newman RA and Chernajovsky Y: 2'-deoxy-5-azacytidine increases binding of cisplatin to DNA by a mechanism independent of DNA hypomethylation. Br J Cancer 67: 209-215, 1993.

57. Bergman AM, Ruiz van Haperen VW, Veerman G, Kuiper CM and Peters GJ: Synergistic interaction between cisplatin and gemcitabine in vitro. Clin Cancer Res 2: 521-530, 1996. 